\title{
Beyond the scope of conflict of interest
}

\author{
Alan BR Thomson MD PhD FRCPC FACP, Robert Enns MD FRCPC, \\ Bill Depew MD FRCPC FACG, Nigel Flook MD CCFP FCFP
}

S ometimes inspiration comes in a flash, sometimes it comes at the end of a rainbow. This viewpoint was no stroke of brilliance, but rather came about from the simple objective of identifying ways to better encourage the best and the brightest general internal medicine (GIM) residents to consider a career in gastroenterology. In our training program at the University of Alberta, we provide an exemplary program of clinical practice in conjunction with intense teaching opportunities, including basic sciences and examination reviews, supported by a mentoring process which helps to match the training program to the trainees' needs. When a promising trainee who has an interest in gastroenterology is identified, he/she is encouraged to participate in our Undergraduate Teaching Program, to undertake a research project with a member of the Division, to participate in weekly gastrointestinal (GI) Rounds, to attend a monthly City Wide Journal Club, and to be nominated for attendance at the Bright Lites Program sponsored by the Canadian Association of Gastroenterology.

There will be instances when these promising young residents believe that they wish to make a career decision for gastroenterology, and although they have watched endoscopic procedures, they have never actually performed these under supervision. Some of the teaching staff carefully select suitable patients, under stable and appropriate circumstances, and the resident who had first seen the patient in consultation is able to watch the complete endoscopy and then spend several minutes of 'hands on' experience to better appreciate one of the joys of gastroenterology: being able to actually see the pathology.

Unfortunately, there is a divided view among teaching staff in terms of whether this is a suitable teaching activity, a useful way to encourage potential new GI residents, and whether only gastroenterology residents (GI Fellows) should actually touch the endoscope. It is recognized that the Royal College encourages GIM residents to have experience with sigmoidoscopies. This is a skill that we do not teach and, of course cannot do so with the 'do not touch the endoscope' rule.

At times, controversy is good because it allows us to focus on the issues and reflect upon what is happening in other training programs. With this in mind, I contacted the training program directors of the adult and pediatric gastroenterology training programs across the country, asking them to volunteer information as to whether and at what level endoscopy experience was provided for GIM or pediatric residents. As anticipated, none of the programs provide extensive training to reach a level of competence comparable to that of a GI Fellow, except under the special circumstances where senior

\begin{tabular}{|c|c|c|}
\hline & $\begin{array}{c}\text { Adult } \\
\text { gastroenterologists }\end{array}$ & $\begin{array}{c}\text { Pediatric } \\
\text { gastroenterologists }\end{array}$ \\
\hline No & 5 & 3 \\
\hline Yes & 6 & 2 \\
\hline
\end{tabular}

GIM residents are going to practice in a remote community where there was an assured employment opportunity requiring endoscopic skills.

The purpose of the survey was to learn how other programs deal with this issue of letting GIM residents 'touch the scope', with the hope that from this we could better determine whether our policy was common throughout the country. Of course, just because others support a different policy does not make them 'right' or us 'wrong', but instead simply provides a background, a benchmark, to allow us to better understand what some of our colleagues are thinking and doing. The results are shown in Table 1.

This information was gathered and then shared with the Program Directors. Out of this discussion came a proposal that the Endoscopy Committee of the Canadian Association of Gastroenterology should be invited to comment, as also should the Royal College Subspecialty Committee in Gastroenterology Program Directors' Committee, and a group of academically oriented family physicians with a special interest in gastroenterology, represented by the Canadian Association of Primary Care Gastroenterology (CanGut) Group. These views were solicited, and we are pleased to provide the input from Drs Robert Enns, Bill Depew and Nigel Flook. As you will see, the Accreditation Committee strongly supports that only gastroenterologists should be provided with intensive training in endoscopy (in addition, of course, to our capable surgical colleagues). This is an important view which is to be respected. Of course, this view does not get away from the initial perspective from which this whole subject started; that is, allowing a handful of highly qualified, interested and motivated GIM residents hoping to choose gastroenterology as a life career to have brief, supervised episodes of hands-on experience to allow them to better understand and appreciate part of the thrill of our subspecialty.

Please consider carefully their views, and share your views by writing to Dr Lloyd Sutherland, Editor-in-Chief of The Canadian Journal of Gastroenterology. 


\section{RESIDENT TRAINING IN ENDOSCOPY: ARE TIMES CHANGING?}

Robert Enns, Chair of the Endoscopy Committee, Canadian Association of Gastroenterology

The training in the use of endoscopy to assess the GI tract has become a hotly debated area in recent years. The provision of this service is now widely disseminated and performed by a variety of physicians and other medical personnel (eg, nurses). There are so many issues to address with this topic that it is difficult to determine which ones have priority for this brief editorial. Summary statements on endoscopic training and practice have been previously published through the American Society for Gastrointestinal Endoscopy and should be reviewed (see suggested reading). To avoid confusion, concise definitions are important:

1. Esophagogastroduodenoscopy: examination of the mucosal surfaces of the esophagus, stomach and proximal duodenum;

2. Colonoscopy: examination of the entire colon and, frequently, the terminal ileum; and

3. Flexible sigmoidoscopy (FS): examination of the rectum, sigmoid and a variable length of colon.

In general, the actual performance of the technical procedure must be included within the context of a broader clinical discipline such as gastroenterology, general surgery or colorectal surgery. The technical aspect of the procedure is often the minor issue; the interpretation and management of the result is more complex. Unfortunately, many endoscopic procedures conclude with an interpretation of normal or abnormal rather than an action plan based on an interpretation of the images. Training should include integration of endoscopy with clinical problem-solving in an atmosphere directed by an experienced endoscopic trainer. Attendance in short courses should not be considered as a substitute for training in an accredited training program. Additionally, privileges should be granted for each separate procedure based on training and assessed by an endoscopic training supervisor. The ability to perform any one endoscopic procedure does not imply competency to perform others.

In the Canadian setting, the situation becomes even more complex. Many hospitals have no strict guidelines for assessing endoscopic competence, and privileges in this area are often based on familiarity rather than objective assessment. Many peripheral hospitals appear to be so enamoured with the presence of an endoscopist that credentialing may be a simple formality, particularly if it is not the area of primary interest.

The assessment of competency in the completion of endoscopic procedures is a difficult problem. Very few studies have been conducted in this area, and those that have been have concentrated on quantity of procedures required to attain a specific goal. This use of threshold procedure numbers at which competence may be globally assessed provides, at best, a rough guide. It must be recognized that trainees develop skills at widely varying rates; however, at least 130 upper endoscopies, 140 colonoscopies and 180 to 200 endoscopic retrograde cholangiopancreatographies are required for the usual trainee to achieve competency. Flexible sigmoidoscopies may be learned quickly, with 20 to 30 procedures; however, these low numbers are simply for screening procedures. The extension of FS for other indications (eg, symptoms) likely requires another level of training.

The discussion above is critical when considering the training of other medical personnel, particularly those with considerably less endoscopic and clinical experience. There are many practicing endoscopists who may have acquired their skills with a minimum of training; however, often these are mature physicians who were forced to adapt to new technology in an immature environment. As the complexity of endoscopy (and gastroenterology) has developed, acceptable standards have also evolved. What may have been acceptable for physicians in previous decades may not be appropriate in the 20th century.

The training of rotating residents in endoscopy is a difficult task. Often, these residents are present for less than a few months, and no attempt at objective assessment of endoscopic skills are undertaken (or, in fact, planned). Many residents early in their career may have never even seen an endoscopy, and may not have had the opportunity to manage any GI disorders. Most institutions, therefore, tend to concentrate on the cognitive aspects of gastroenterology rather than the technical aspects. This would seem appropriate; however, most institutions appear to characterize different rotating specialties in a varied manner, some being permitted to learn endoscopy in a short period of time and others not. Clearly, this dichotomy requires resolution.

It is accepted that no resident can learn gastroenterology in a few months; that is why gastroenterology training is, at minimum, two years. A decision must be made regarding the goals and objectives of teaching gastroenterology to a rotating resident. The realistic expectation is to give the resident a 'flavour' of gastroenterology with an understanding of the key concepts. Recognition of disease patterns, their diagnosis and management are the utmost priority with this training. Endoscopic examinations should not be the highest priority.

With this understood, why then is there continual debate and discussion regarding training endoscopy in only a few months? It is clear that it cannot be taught to a high level in this short period of time; therefore, a substandard level is deemed acceptable to some. The single exception to this may be with screening FS, where only a small number of procedures are required for this indication. However, screening sigmoidoscopy is not universally accepted for colon cancer screening, and the evolution of endoscopy has now moved towards colonoscopy as the colon cancer screening modality of choice.

Perhaps the most important aspect to consider when 'permitting' technical training to rotating residents is the goals and objectives of this endeavour. One objective may be simply to enhance the experience in gastroenterology. The resident is often thrilled with the opportunity to manipulate the instrument. This objective is relatively easy to meet; however, it should be understood that endoscopic adequacy requires a great deal more. If the objective is reaching a specific number of procedures for documentation purposes (and subsequent credentialing), this is a different issue. As noted in the preamble, competency requires considerably more than simply a specified number of procedures.

Are there conclusions that one can draw? Where we have little data, we can have little for evidence-based conclusions. Perhaps the view of the patient should be the most important aspect. In this era of gastroenterology, the long-term value of a few months of technical training seems woefully inadequate. The expectations of patients, I believe, exceed the level of 
minimal accepted standards for endoscopy. Although an experience of endoscopy may be enjoyable and useful to residency training programs, an expert in endoscopy it does not make.

\section{SUGGESTED READING}

1. Risk management for the GI Endoscopist. American Society for Gastrointestinal Endoscopy. Prepared by the ASGE ad hoc Management Committee. May 2001.

2. Appropriate Use of Gastrointestinal Endoscopy. A consensus statement from the ASGE. September 2000.

3. Policy and Procedure Manual for Gastrointestinal Endoscopy. Guidelines for training and Practice. Update instructions. ASGE, June 2001.

4. Hospital credentialing standards for physicians who perform endoscopy. Gastroenterology 1993;104:1563.

5. American Society for Gastrointestinal Endoscopy. Principles in training in gastrointestinal endoscopy. From the ASGE. Gastrointest Endosc 1999;49:845-53.

6. Grendell JH. Endoscopy training in a three-year curriculum. Gastrointest Endosc Clin N Am 1995;5:293-7.

7. Friedman LS. How long does it take to learn endoscopy? Gastrointest Endosc 1995;42:371-3.

8. Jowell PS, Baillie J, Branch MS, Affronti J, Browning CL, Bute BP. Quantitative assessment of procedural competence. A prospective study of training in endoscopic retrograde cholangiopancreatography. Ann Intern Med 1996;125:983-9.

$<$ www.annals.org/cgi/content/full/125/12/983> (Version current at January 21, 2005)

\section{VIEWPOINT: TRAINING FOR ENDOSCOPIC COMPETENCE}

Bill Depew, Chair, RCPSC Specialty Committee in Gastroenterology National Specialty Society Liaison

Gastrointestinal endoscopy has evolved rapidly since its initial incorporation into routine clinical management. What was once a novel, dedicated diagnostic tool has morphed into a diagnostic and therapeutic modality with multiple applications in modern practice. In Canada, endoscopic procedures are performed predominantly by gastroenterologists and general surgeons trained and certified in accredited postgraduate programs of the Royal College of Physicians and Surgeons of Canada (or equivalent). With the expanding roles of different types of endoscopic intervention comes the imperative to ensure that all endoscopists - future and already certified receive adequate training to enable optimal patient care in terms of efficacy, safety and cost-effectiveness. Endoscopic interventions that are ill-conceived or executed nonexpeditiously without due regard for individual patient safety are not acceptable. Endoscopic practice that results in substandard rates of lesion detection or interpretation and correspondingly misguided therapeutic decisions should not be tolerated.

Endoscopy was invented by and has been continuously advanced and refined by gastroenterologists. To achieve the goal of optimal patient care in endoscopic practice, accredited Royal College programs in gastroenterology have accepted a primary responsibility for endoscopic training nationwide. These programs operate endoscopic teaching units that bring trainees to appropriate levels of competence through a carefully planned curriculum that demands the coordinated development of both technical and cognitive endoscopic skills. Each trainee is evaluated in a closely supervised environment and in a manner that allows the trainee to mature, in a graduated fashion, into independent, competent endoscopic practice. Such programs also address the equally important issues of endoscopic unit design and function, infection control, the principles and uses of electrosurgical equipment, radiation safety and the critical role of quality assurance and improvement.

While the rates of acquisition of endoscopic skills vary from individual to individual, there is consensus that competence requires the attainment of at least a threshold number of cases for each particular (elective or emergent) type of endoscopic intervention $(1,2)$. Only after a trainee reaches these thresholds can any attempt at an assessment of competency be undertaken. For the majority of gastroenterology trainees, it is necessary to commit at least 18 months of clinical training to master the common interventions (esophagogastroduodenoscopy, colonoscopy and FS) used in practice. Available caseloads, individual skill acquisition rates, integration of nontechnical instruction, expansion of clinical knowledge databases and the frequencies of therapeutic opportunities influence this training interval.

Several Canadian gastroenterology training programs have evolved collaborative systems to assist in the training of general surgical residents who will integrate endoscopy into their practice activities. In other instances, appropriate endoscopic training is provided as an integral part of the surgical residency. While the initial period of instruction within the gastroenterology-directed rotations may be shorter, most trainees continue to practice endoscopy with their experienced general surgical supervisors, thereby expanding, in a critical way, the total endoscopic training experience.

In the past, Canadian gastroenterology training programs have, from time to time, experimented with training models which were designed ad hoc to provide selective endoscopic skills to a limited number of nongastroenterologist medical specialists. Such training was offered ostensibly to meet certain needs in underserviced areas where formally trained and certified gastroenterologists were unavailable. In many cases, this training was short in time and limited in scope, with virtually no attention to the crucial matters of endoscopy unit structure and function, infection control, quality control and improvement, proctoring or continuing medical education. Unfortunately, such trainees may proceed to perform interventions for which they were not trained. In my own experience, two of three individuals were performing colonoscopy without proper training and all three were engaged in endoscopy in emergency situations in which their training was quite incomplete. Only one of these actually began independent practice in an underserviced region. Whether these practitioners are working in properly equipped and monitored endoscopy units with appropriately trained endoscopy nurses and support staff and programs of quality control and assurance is unknown. Moreover, there may be increases in misinterpretation of endoscopic findings and miss rates for lesions that are grossly abnormal, which are probably substandard. Data on these later points are lacking, and (anecdotal) opinions vary. Studies have shown better outcomes for cardiac patients managed by cardiologists (3), dialysis cases managed by nephrologists (4) and upper GI bleeding managed by gastroenterologists (5) when compared with management by general internists, but it is very unlikely that comparisons of the conduct and outcome of endoscopic practice among practitioners trained in different ways will ever be done. There are data, however, that clearly document poorer technical performance among trainees with truncated teaching. For example, certified gastroenterologists consistently achieve cecal intubation rates approaching $95 \%$ $(6,7)$. Trainees in certified programs achieve rates of $84 \%$ after 
100 procedures (8). Primary care physicians with limited training report cecal intubation rates of $54 \%$ to $83 \%(9,10)$. For upper endoscopy, experienced endoscopists approach 100\% success (8), while inadequately trained practitioners report duodenal intubation rates at $93 \%$ (11).

Given the aforementioned carefully considered requirements for proper training in all aspects of endoscopic practice, it is difficult to conceive of successful achievement of these objectives in any program that is less comprehensive in either scope or detail. Some would take the view that endoscopy is just a collection of technical procedures which can be mastered without much fuss by any reasonably competent practitioner. Indeed, I was once told by a prominent academic Canadian general internist that "a monkey could be taught to do endoscopy". While I would not dispute the rapid acquisition of the technical capability of esophageal and pyloric intubation by some gifted individuals, endoscopy is far more than simply inserting a scope into a hollow viscus. To suggest that endoscopic training can be accomplished in less time with fewer cases, less supervision or less attention to the issues which are not directly procedure-related is to ignore the responsibility we have as clinicians to provide the highest quality patient care expeditiously, safely and in the interest of improving outcomes.

The practice of gastroenterology has changed. It is no longer a 'spectator sport'. In the past, diagnostic upper endoscopy for dyspepsia or chronic pyrosis was frequent. Now, alternate algorithms provide evidence-based, nonendoscopic options for management. Colonoscopic screening has emerged as a major player in endoscopic practice but this procedure cannot be learned by individuals who have done some upper endoscopy as the starting point, and it is more difficult to accomplish and requires the ability to execute polypectomy routinely. The 'need' for a simple, easy-to-master diagnostic service is virtually nonexistent. Endoscopists should now 'look' with the intention and ability to do something clinically useful. The evidence supporting this approach in improving patient outcomes continues to mount.

In view of the complexities of endoscopic practice, the Gastroenterology Specialty Committee of the Royal College of Physicians and Surgeons and the national gastroenterology program directors have unanimously adopted the position that there is no place for 'part-time' endoscopists in Canada - a position endorsed by the Canadian Association of Gastroenterology (1) and the American Society of Gastrointestinal Endoscopy (2). Accordingly, it is recommended that training in endoscopic practice should be delivered in accordance with the rigorous standards that regulate Canadian gastroenterology training programs using methods currently in operation in those programs (or their equivalents). Anything less is irresponsible.

\section{REFERENCES}

1. MacSween HM. Canadian Association of Gastroenterology Practice Guideline for granting of privileges to perform gastrointestinal endoscopy. Can J Gastroenterol 1997;11:429-32.

2. Principles of training in gastrointestinal endoscopy. From the ASGE. American Society for Gastrointestinal Endoscopy. Gastrointest Endosc 1999;49:845-53.

3. Casale PN, Jones JL, Wolf FE, Pei Y, Eby LM. Patients treated by cardiologists have a lower in-hospital mortality for acute myocardial infarction. J Am Coll Cardiol 1998;32:885-9.

4. Kshirsagar AV, Hogan SL, Mandelkehr L, Falk RJ. Length of stay and costs for hospitalized hemodialysis patients: Nephrologists versus internists. J Am Soc Nephrol 2000;11:1526-33.
5. Quirk DM, Barry MJ, Aserkoff B, Podolsky DK. Physician specialty and variations in the cost of treating patients with acute upper gastrointestinal bleeding. Gastroenterology 1997;113:1443-8.

6. Winawer SJ, Zauber AG, O'Brien MJ, et al. Randomized comparisons of surveillance intervals after colonoscopic removal of newly diagnosed adenomatous polyps. The National Polyp Study Workgroup. N Engl J Med 1993;328:901-6.

7. Rex DK, Lehman GA, Ulbright TM, et al. Colonic neoplasia in asymptomatic persons with negative fecal occult blood tests: Influence of age, gender, and family history. Am J Gastroenterol 1993;88:825-31.

8. Cass OW, Freeman ML, Peine CJ, Zera RT, Onstad GR. Objective evaluation of endoscopy skills during training. Ann Intern Med 1993;118:40-4.

9. Godreau CJ. Office-based colonoscopy in a family practice. Fam Pract Res J 1992;12:313-20.

10. Rodney WM, Dabov G, Cronin C. Evolving colonoscopy skills in a rural family practice: The first 293 cases. Fam Pract Res J 1993;13:43-52.

11. Rodney WM, Weber JR, Swedberg JA, et al. Esophagogastroduodenoscopy by family physicians phase II: A national multisite study of 2,500 procedures. Fam Pract Res J 1993;13:121-31.

\section{ENDOSCOPY TRAINING - THE CANGUT PERSPECTIVE}

Nigel Flook, President of CanGut

CanGut has a strong interest in the issue of competency in GI endoscopic procedures. This interest extends beyond the standards needed by GIM residents and includes issues affecting many other professionals involved in this area of practice. CanGut's goal is to have sufficient access to GI endoscopies with sufficient quality to allow optimal health outcomes for our patients regardless of whether gastroenterologists or other professionals perform the procedures.

The Canadian health care system cannot meet the present needs for timely endoscopy due to limited access to gastroenterologists. Patients often experience long waits for GI consultations and procedures, sometimes with serious adverse health consequences. Many individuals living in rural communities face additional risks and inconvenience due to the need to travel long distances from homes, loved ones and care givers to access these services.

Increased uptake by primary care physicians of guidelines for surveillance and screening of GI conditions such as colorectal cancer, Barrett's esophagus and inflammatory bowel disease will increase demands for GI endoscopy in the years to come. The population of Canada continues to grow, and an aging population will have greater need for GI services, yet the production of new full-time clinical gastroenterologists is failing to keep pace. Innovative and creative solutions will be needed as the demand for GI endoscopies increases.

People living in remote, isolated or under-serviced regions have a right to expect the same standards of care as those living near an academic tertiary care centre. These procedures must be provided with technical skill and professional knowledge sufficient to allow acceptable safety and competent interpretation. Primary care physicians will rely on these procedures and an interpretation of the results to support clinical decisionmaking and patient management.

GI endoscopy is unlike many imaging techniques in that there may be the potential for tissue diagnosis and other diagnostic testing as well as the potential for therapeutic interventions. Many issues are just as important as the technical skill needed to pass the endoscope. These issues include when to scope, how often to scope, what has been seen, when to 
perform other diagnostic tests, the ability to perform diagnostic and therapeutic interventions during the procedure, how to interpret the results of the procedure, when is normal truly normal and when is an abnormal result clinically significant. Do our patients consider it acceptable for an endoscopist to be unable to remove polyps discovered during a screening colonoscopy? Unnecessary duplication of services must be minimized where possible.

In many ways, GI endoscopy is similar to the issue of appropriate access to obstetrical services across Canada. The population's need for obstetrical services exceeds the medical profession's ability to manage these services exclusively through trained specialists. National standards are often not available to the institutions faced with the challenge of granting privileges to physicians for services that are in high demand. Many individuals have been grandfathered into privileging and it is rare to find effective programs designed to ensure continuing competency through ongoing or periodic reviews of performance. It is no longer enough for health service providers to meet a standard for competency only at the completion of a training program. The present expectation is to be able to demonstrate continuing competency by measurements of performance on a periodic or ongoing basis.

These problems are far too complex to be resolved simply by agreement about training standards or numbers of types of procedures that must be performed before certification is granted or privileges are extended.

Balancing limited human and health care resources against the legitimate needs of our patients is challenging. The solution will likely include recognizing the value of multidisciplinary teams, electronic information systems and advanced practice skill development for many health professionals. Comprehensive and integrated approaches will bring us closer to the desired outcomes in complex clinical situations such as these.

Competency to perform GI endoscopic services cannot be managed as a single entity. We must separate the aspects of technical skill development from cognitive skill and decisionmaking abilities. Certification of technical competency can be based on the completion of a requisite number of procedures. The approximate number of procedures needed to demonstrate technical competency has been determined for the commonest GI endoscopic procedures. Professionals who have demonstrated this technical skill could provide needed services when connected to multidisciplinary teams involving gastroenterologists. These teams may be located under the same roof or connected by electronic information systems. The important issue is to partner with subject experts who have the cognitive and professional skills needed to support decision-making based on a procedure that is provided with technical skill. The most dangerous situation is an individual practicing in isolation and unaware of important information that could affect clinical decision-making.

Studies will need to be performed to determine the number of procedures needed for various groups of candidates such as candidates in training programs and individuals in practice including GIM, family medicine, advanced nursing practices and technicians.

The technical and cognitive skills and the professional knowledge needed to support the complete range of decisionmaking and interventions in relation to GI endoscopy is extensive and likely will require the full extent of a gastroenterology residency training program to allow the acquisition of competency.

Competency for subsets of these activities will need to be based on a careful categorization of:

- the indications for GI endoscopy;

- a risk assessment based on the clinical situation;

- the degree of support available from a multidisciplinary team;

- the support services such as surgery, internal medicine and intensive care units available; and

- the various interventions that may be required during the procedure.

Training programs will need to complete this categorization and identify the markers for competency among candidates with a variety of backgrounds.

Privileges to perform GI endoscopy would be based on the initial certification of competency and a demonstration of continuing competency for all practitioners providing these services. The requirement to demonstrate continuing competency will not be popular with physicians but it is a reality. Peers would set the standards and define the measurements of continuing competency following the principles of selfregulation that guide our profession.

The need to define the training standards for GIM residents to perform GI endoscopy has forced gastroenterologists, licensing authorities and the profession as a whole to deal with these issues in a more comprehensive fashion. The solutions will be complex and innovative. They will integrate many assets in the health care system. They will necessitate the use of information technology and properly functioning multidisciplinary teams. We should expect significant changes as we begin to deal with these issues. 


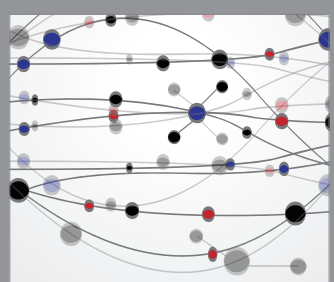

The Scientific World Journal
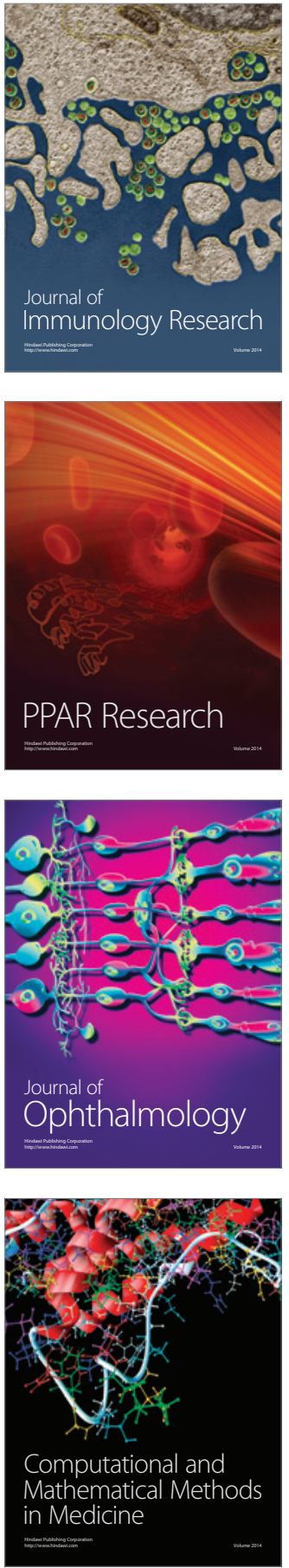

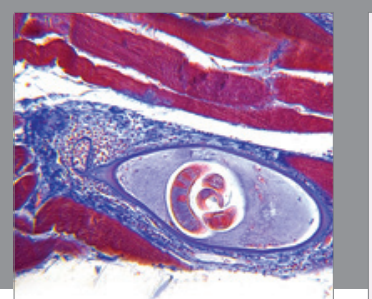

Gastroenterology Research and Practice

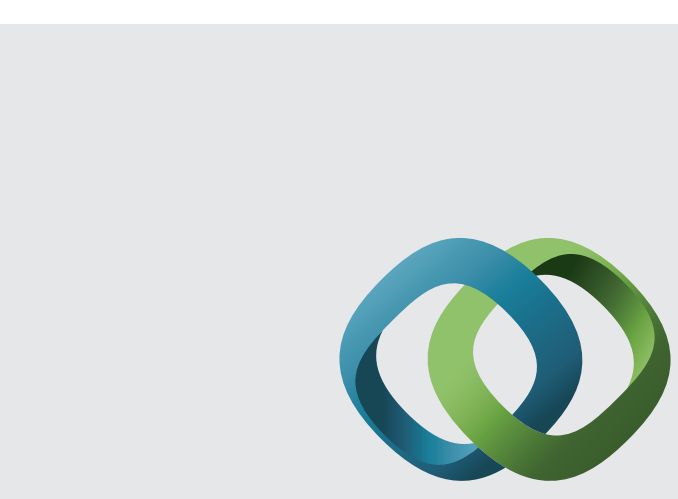

\section{Hindawi}

Submit your manuscripts at

http://www.hindawi.com
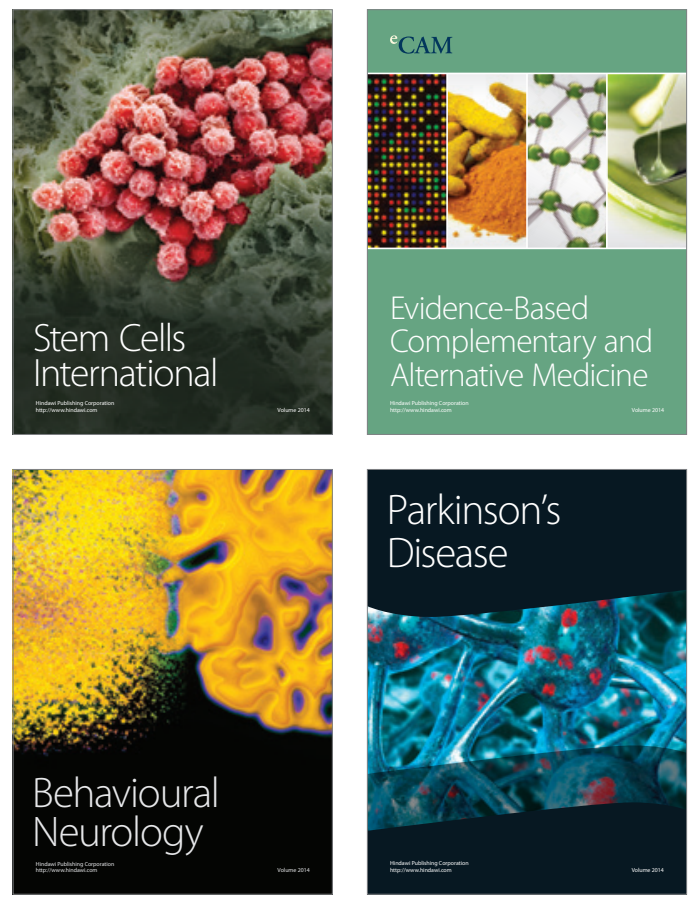
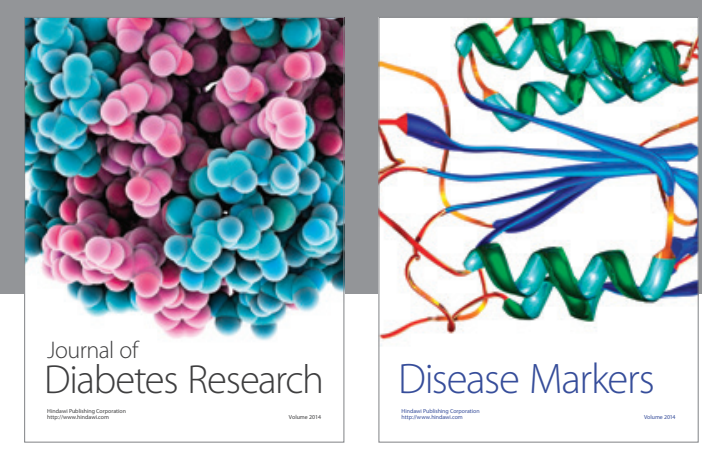

Disease Markers
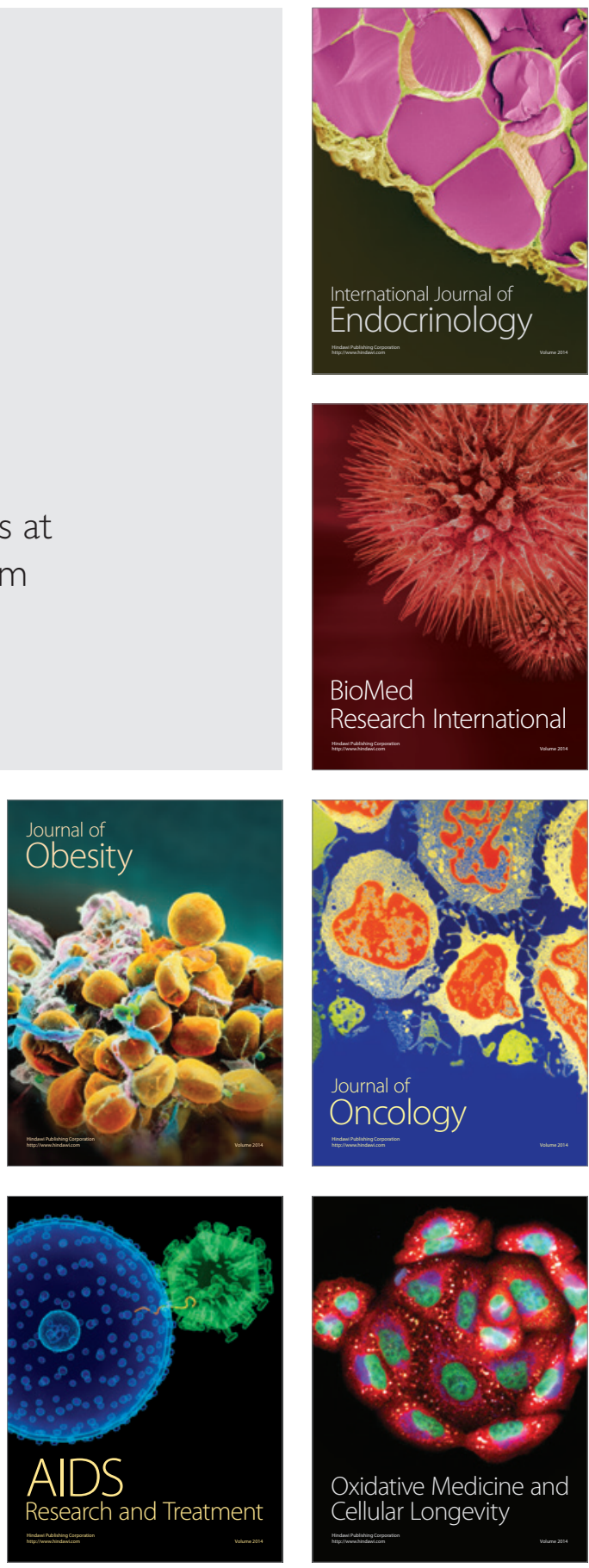